\title{
Assessment of Renal Function in Post-Liver Transplant HCV-Positive Patients Treated with Direct Acting Antivirals
}

This article was published in the following Dove Press journal: International Journal of Nephrology and Renovascular Disease

\author{
Khaled Elzorkany (iD) ${ }^{1,2}$ \\ Mahmoud Abd-Elaziz Kora' \\ Aliaa Sabry Abdel Wahed ${ }^{3}$ \\ Hassan El-Sayed Zaghla ${ }^{3}$ \\ Ahmed Mohamed Zahran (iD) \\ Yassein Salah Yassein' \\ Asmaa Zaki El Naggar ${ }^{4}$ \\ Abdallah Essa (iD ${ }^{5}$ \\ Abdelnaser Abdelaty Gadallah ' \\ 'Internal Medicine Department, Faculty \\ of Medicine, Menoufia University, Shibin \\ El-Kom, Egypt; ${ }^{2}$ Internal Medicine \\ Department, College of Medicine, King \\ Faisal University, Al-Ahsa, Saudi Arabia; \\ ${ }^{3}$ Hepatology and Gastroenterology \\ Department, National Liver Institute, \\ Menoufia University, Shibin El- Kom, \\ Egypt; ${ }^{4}$ Menshawy Hospital, Tanta, Egypt; \\ ${ }^{5}$ Tropical Medicine Department, Faculty \\ of Medicine, Menoufia University, Shibin \\ El-Kom, Egypt
}

Correspondence: Khaled Elzorkany Internal Medicine Department, Faculty of Medicine, Menoufia University, Shebin ElKom, Menoufia, Egypt

Tel 00201002827630

Email khaledelzorkany@med.menofia. edu.eg
Purpose: Direct acting antiviral agents (DAAs) have greatly improved the clearance of hepatitis $\mathrm{C}$ virus (HCV) infection. The effect of DAAs on renal function in post-liver transplant HCV-positive patients remains questionable, especially considering the possibility of drug interactions between immunosuppressants and DAAs.

Patients and methods: A retrospective observational study included 84 post-liver transplant patients with HCV infection. Patients were divided into two groups: group I received sofosbuvir plus ribavirin for 24 weeks, group II received sofosbuvir plus daclatasvir for 12 weeks. Laboratory data and eGFR were determined before, at the end, and 6 months after completion of treatment.

Results: The treatment was well tolerated with $100 \%$ sustained virologic response (SVR 12). There was no statistically significant difference between the two groups regarding clinical and laboratory data before treatment. Mean eGFR significantly reduced from 87.36 $\mathrm{mL} / \mathrm{min}$ to $76.16 \mathrm{~mL} / \mathrm{min}$ in group I $(P=0.001)$. However, within 6 months after treatment, mean eGFR recovered to $81.51 \mathrm{~mL} / \mathrm{min}$, which was not significant when compared to baseline eGFR $(P=0.09)$. Mean eGFR in group II showed non-significant change. There were no significant changes in immunosuppressive drug levels and eGFR in either group of patients, who received either ciclosporin or tacrolimus before and at the end of treatment.

Conclusion: DDAs in post-liver transplant patients with HCV infection were well tolerated and associated with stable renal function. Moreover, sofosbuvir plus daclatasvir regimen showed relatively better renal safety compared to sofosbuvir plus ribavirin.

Keywords: renal function, hepatic transplantation, direct acting antiviral agents, hepatitis $\mathrm{C}$ treatment

\section{Introduction}

Hepatitis $\mathrm{C}$ virus (HCV) infection is one of the most common causes of chronic liver disease worldwide, with approximately 70 million infected patients, of whom $15-30 \%$ go on to develop cirrhosis with 3-5\% annual risk of hepatocellular carcinoma. $\mathrm{HCV}$ is one of the most common indications for liver transplantation globally. ${ }^{1}$ These complications of hepatitis $\mathrm{C}$ can be prevented if antiviral therapy is given before the occurrence of advanced hepatic disease, especially in children and young adults. ${ }^{2} \mathrm{HCV}$ allograft infection is inevitable after liver transplantation (LT). About $30 \%$ of patients develop liver cirrhosis within 5 years post-transplantation. Eradication of HCV infection in post-LT patients is a concern due to faster cirrhosis progression in hepatic allografts. ${ }^{3,4}$ The treatment of HCV infection with SVR 
achievement has many advantages regarding risk reduction of liver decompensation and hepatocellular carcinoma, improved survival and outcomes, even in patients with severe hepatic disease. ${ }^{5}$

Past treatment with interferon and ribavirin for recurrent liver graft infection with hepatitis $\mathrm{C}$ virus, despite its positive impact on survival, had several side-effects, such as low SVR (15-35\%), a high discontinuation rate (up to $40 \%$ ), and significant drug-drug interactions. ${ }^{6}$ Currently, the direct-acting antivirals (DAAs) are considered the treatment of choice for $\mathrm{HCV}$ infection. Recently, almost all clinical guidelines recommend therapy of HCV RNA positive patients regardless of underlying liver disease severity and levels of serum alanine amino transferase. ${ }^{7,8}$ DAAs have better results in management of $\mathrm{HCV}$ infection, with more than $95 \%$ of cases demonstrating sustained virologic response 12 weeks post-treatment (SVR 12) in non-cirrhotic candidates, and 90-95\% in advanced and decompensated cirrhosis. ${ }^{9}$ Although eradication of $\mathrm{HCV}$ infection before LT while on the waiting list is the option to avoid reinfection of the graft, this may not be available and practical in all cases. ${ }^{10}$ There are selected regimens of DAAs tested for treatment of $\mathrm{HCV}$ infection post-LT. Studies have shown cure rates of greater than $90 \%$ in most patients. ${ }^{1-17}$ However, there is restricted clinical information on the safety and efficacy of these regimens in LT patients.

The incidence of renal impairment is $40 \%$ higher in $\mathrm{HCV}$ positive patients compared to $\mathrm{HCV}$ negative individuals. HCV-induced renal impairment ranges from mild to end-stage renal disease, and it commonly complicates the treatment outcome of $\mathrm{HCV}$ infection. ${ }^{18}$ Furthermore, drug-drug interactions are a major concern regarding renal safety, when treating $\mathrm{HCV}$ patients in the setting of immunosuppressive drugs post-LT, while some DAAs need no dose adjustment, others require meticulous dose adjustment when given concomitantly with immunosuppressive therapy. ${ }^{5}$

The aim of this work was to evaluate the effect of DAAs on renal function in post-liver transplant patients with chronic hepatitis $\mathrm{C}$ virus infection at the end and after the completion of treatment.

\section{Patients and Methods}

Our retrospective observational study included 84 postliver transplant Egyptian patients followed up at the National liver Institute in Shebin-Elkom (Egypt) from March 2017 to December 2019. Inclusion criteria were:
1) age $>18$ years; 2) positive HCV-RNA at the time of transplantation; 3) no history of previous HCV treatment before transplantation; and 4) acceptable kidney function (eGFR above $60 \mathrm{~mL} / \mathrm{min}$ ). After liver transplantation, all patients started DAAs with no previous attempts of treatment for $\mathrm{HCV}$. Patients were divided into two groups according to the DAAs regimen received. Group I received sofosbuvir plus ribavirin (51 patients, 60.7\%) for 24 weeks $(\mathrm{EOT}=24)$, and group II received sofosbuvir plus daclatasvir (33 patients, 39.3\%) for 12 weeks $(\mathrm{EOT}=12)$. A sustained virological response was defined at 12 weeks following the completion of treatment $(\mathrm{SVR}=12)$.

Baseline laboratory data and eGFR were determined before treatment initiation, at the end of treatment (EOT=24 weeks for group I, and 12 weeks for group II), and 6 months after the completion of treatment. The Chronic Kidney Disease Epidemiology Collaboration (CKD EPI) equation was used to estimate GFR. ${ }^{19}$ All patients were maintained on Calcineurin inhibitors (either Ciclosporin or tacrolimus). Ciclosporin level 2 hours postdose (C2) and tacrolimus trough level were determined monthly during the period of treatment. ${ }^{20}$ The research protocol was approved by the Institutional Research Board and Ethical Committee of the National Liver Institute, Menoufia University. All data were collected and analyzed to ensure data integrity and patient privacy. The organs were donated voluntarily with written informed consent, and the transplantations were conducted in accordance with the Declaration of Istanbul.

\section{Statistical Analysis}

Data were analyzed using Statistical Package for Social Science (SPSS) program for windows version 22 (SPSS Inc. Chicago, IL, USA) and Microsoft excel. Numerical data were expressed as mean and standard deviation (SD), while categorical data were expressed as number and percentage. Chi square $\left(X^{2}\right)$ was used to compare two groups of categorical data. Independent $t$-test and Mann Whitney test were used as appropriate to compare two groups of quantitative variables, while paired $t$-test was used to compare results of one group before and after treatment. All statistical analyses were based on twosided hypothesis tests with a significance level of $P<0.05$.

\section{Results}

This retrospective study included 84 post-liver transplant $\mathrm{HCV}$ positive patients divided into two groups. Group I 
included 51 patients who received sofosbuvir plus ribavirin for 24 weeks: Group II included 33 patients who received sofosbuvir plus daclatasvir for 12 weeks. There was no statistically significant difference regarding demographics (age, gender, HCC, DM, hypertension, duration of transplantation, and immunosuppression) and pretreatment laboratory (bilirubin, albumin, ALT, AST,ALP, INR, HbA1C, Na, K, CRP, Hb, WBC, platelets, uric acid, urea, creatinine, and eGFR) data between the two studied groups (Table 1). Urine analysis was done for all patients with no specific findings are present as possible markers of kidney disease. All patients tolerated treatment well with $100 \%$ clearance of virus at the end of treatment (EOT) and at 12 weeks of completion of treatment (SVR 12). At the end of treatment eGFR was found to be significantly lower in group I $(76.16 \mathrm{~mL} / \mathrm{min})$ compared to group II $(86.00$ $\mathrm{mL} / \mathrm{min}$ ) with a $P$-value $=0.03$ (Figure 1 ). eGFR significantly reduced from $87.36 \mathrm{~mL} / \mathrm{min}$ (pre-treatment) to $76.16 \mathrm{~mL} / \mathrm{min}$ (EOT) in group I with a $P$-value $=0.001$ (Figure 1). However, within 6 months after the completion of treatment, eGFR recovered to $81.51 \mathrm{~mL} / \mathrm{min}$ with no statistically significant difference when compared to baseline eGFR before treatment $(P$-value $=0.09)$. There was no significant change in eGFR in group I (Figure 1). INR, ALT, AST, uric acid, urea, and creatinine were found to be significantly increased, while platelets were significantly reduced at the end of treatment with a combination of Sofosbuvir plus ribavirin (Table 2). Uric acid and platelets were the variables that showed a significant increase and decrease, respectively, at the end of treatment in the group treated with a combination of Sofosbuvir plus Daclatasvir (Table 2). All the parameters improved within 6 months after completion of treatment in both groups (data not shown). There was no statistically significant change in eGFR in patients who received cyclosporine as compared to those who received tacrolimus (Figure 2).

\section{Discussion}

Since the advent of DAAs, the pattern of HCV treatment has changed dramatically. Compared to previous regimens involving pegylated interferon and ribavirin, these recent agents have a very safe profile and higher rates of SVR of more than $95 \%$ with a shorter course of treatment. ${ }^{21}$ Positive HCV patients at operation time almost always show graft infection with $\mathrm{HCV}$. Complications of $\mathrm{HCV}$ reinfection such as graft dysfunction, cirrhosis, and higher death rates are more common in LT patients than nontransplant patients. ${ }^{22}$ There is a significant reduction of morbidity and mortality after liver transplantation with eradication of $\mathrm{HCV}$ infection. ${ }^{23}$

Short-term follow-up of DAAs treatment showed better tolerance and acceptable drug-drug interactions, so this treatment is by all accounts suitable both pre- and postliver transplantation. ${ }^{24-26}$ However, eradication of $\mathrm{HCV}$ infection in post-LT patients remains challenging with potential drug-drug interactions. ${ }^{27,28}$

According to our results, these combination treatments were well tolerated and there was no termination of treatment experienced by any of our patients due to adverse events. All studied patients achieved sustained virological response at week 12 after the completion of treatment (SVR 12) with a $100 \%$ success rate.

Fortunately, we noticed no serious adverse events on the graft function, as no patient encountered a graft rejection, dysfunction, or required re-transplantation amid or following the antiviral treatment, and this was also reported in previous different studies. ${ }^{29,30}$ One of these studies showed that DAAs combination treatment was much better tolerated with no significant side-effects and no encountered acute rejection with tissue biopsy and having clearly better efficacy than the previous studies using a first-generation protease inhibitor with pegylated interferon (Peg-IFN) and ribavirin. ${ }^{12}$

The major target in antiviral treatment for chronic hepatitis $\mathrm{C}$ is sustained virological response, which is typically accompanied by normalization of aminotransferase levels. Some patients, especially those with advanced liver disease, however, show persistent hepatic injury after HCV cure. ${ }^{31}$ Interestingly, our study revealed mild elevation of aminotransferases at the end of treatment compared to pretreatment levels; however, this elevation was improved 6 months after completion of therapy. In concordance with the demographic and laboratory findings of our study, Welsch et $\mathrm{al}^{32}$ demonstrated factors like male gender, Gamma-glutamyl transferase, and markers of advanced liver disease to be baseline factors that were significantly associated and correlated with ongoing elevation of ALT levels after SVR; however, this was in treatment of chronic hepatitis $\mathrm{C}$ infection without liver transplantation.

Regarding the assessment of renal function while using DAAs in post-liver transplant patients infected with hepatitis $\mathrm{C}$ virus, patients treated with sofosbuvir plus ribavirin (group I) showed a significant reduction of the eGFR at the end of treatment from $87.36 \mathrm{~mL} / \mathrm{min}$ to $76.16 \mathrm{~mL} / \mathrm{min}$, but still in the normal range, also there was a significant increase in serum urea, creatinine, and uric acid at the 
Table I Clinical and Laboratory Data of the Two Studied Groups Before Treatment

\begin{tabular}{|c|c|c|c|c|}
\hline Variables & $\begin{array}{l}\text { Group I Sofosbuvir + Ribavirin } \\
(n=51)\end{array}$ & $\begin{array}{l}\text { Group II Sofosbuvir + Daclatasvir } \\
(n=33)\end{array}$ & Test & $P$ \\
\hline Age (years) & $52.63 \pm 4.44$ & $50.85 \pm 6.26$ & 1.52 & 0.131 \\
\hline \multicolumn{5}{|l|}{ Gender: } \\
\hline Male (n) (\%) & $38(74.5)$ & $28(84.8)$ & $1.27^{*}$ & 0.29 \\
\hline Female (n) (\%) & $13(25.5)$ & $5(15.2)$ & & \\
\hline \multicolumn{5}{|l|}{ HCC: } \\
\hline Yes (n) (\%) & $12(23.5)$ & $5(13.3)$ & $0.87^{*}$ & 0.26 \\
\hline No (n) (\%) & $39(76.5)$ & $28(85.7)$ & & \\
\hline \multicolumn{5}{|l|}{ Diabetes: } \\
\hline Yes (n) (\%) & $4 \mathrm{I}(80.4)$ & $28(84.8)$ & $0.27^{*}$ & 0.77 \\
\hline No (n) (\%) & $10(19.6)$ & $5(15.2)$ & & \\
\hline \multicolumn{5}{|l|}{ Hypertension: } \\
\hline Yes (n) (\%) & $43(84.3)$ & $30(90.9)$ & $0.77^{*}$ & 0.52 \\
\hline No (n) (\%) & $8(15.7)$ & $3(9.1)$ & & \\
\hline \multicolumn{5}{|l|}{ Immunosuppression } \\
\hline Tacrolimus (n) (\%) & $39(76.5)$ & $25(75.8)$ & $0.006 *$ & 1.00 \\
\hline Ciclosporin (n) (\%) & $12(23.5)$ & $8(24.2)$ & & \\
\hline Duration of Tx (years) & $8.18 \pm 1.62$ & $7.61 \pm 1.22$ & $1.73^{\#}$ & 0.09 \\
\hline $\begin{array}{l}\text { Start of treatment after transplantation } \\
\text { (years) }\end{array}$ & $3.14 \pm 0.80$ & $2.91 \pm 0.27$ & $1.32^{\#}$ & 0.19 \\
\hline Tacrolimus trough level (ng/mL) & $6.67 \pm 3.43$ & $6.00 \pm 2.08$ & $0.87^{\#}$ & 0.39 \\
\hline Ciclosporin C2 level (ng/mL) & $365.92 \pm 132.55$ & $350.14 \pm 84.90$ & $0.001^{\$}$ & 0.99 \\
\hline Bilirubin (mg/dL) & $1.08 \pm 0.47$ & $1.09 \pm 0.55$ & $-0.09^{\#}$ & 0.95 \\
\hline Albumin (g/L) & $3.82 \pm 0.75$ & $3.88 \pm 0.55$ & $-1.03^{\#}$ & 0.30 \\
\hline ALT (IU/L) & $45.20 \pm 22.83$ & $49.2 I \pm 24.7 I$ & $-0.78^{\#}$ & 0.45 \\
\hline AST (IU/L) & $55.7 I \pm 40.36$ & $43.88 \pm|7.9|$ & $-0.82^{\$}$ & 0.75 \\
\hline ALP (IU/L) & $234.57 \pm 205.45$ & $202.70 \pm 112.69$ & $0.8 I^{\$}$ & 0.42 \\
\hline INR & $0.99 \pm 0.07$ & $1.02 \pm 0.11$ & $-1.23^{\#}$ & 0.22 \\
\hline $\mathrm{Hb} \mathrm{Alc}$ & $5.66 \pm 1.25$ & $5.62 \pm 0.99$ & $0.17^{\#}$ & 0.87 \\
\hline $\mathrm{Na}(\mathrm{mmol} / \mathrm{L})$ & $|35.4| \pm 4.28$ & $135.76 \pm 3.93$ & $-0.37^{\#}$ & 0.71 \\
\hline $\mathrm{K}(\mathrm{mmol} / \mathrm{L})$ & $4.44 \pm 0.53$ & $4.60 \pm 0.56$ & $-1.32^{\#}$ & 0.19 \\
\hline CRP & $7.35 \pm 5.35$ & $8.29 \pm 6.50$ & $-0.32^{\$}$ & 0.75 \\
\hline $\mathrm{Hb}(\mathrm{g} / \mathrm{dL})$ & $|3.2| \pm 2.0 \mid$ & $13.64 \pm 1.63$ & $-1.03^{\#}$ & 0.31 \\
\hline WBCs & $6.07 \pm 1.93$ & $5.63 \pm 1.99$ & $1.007^{\#}$ & 0.32 \\
\hline Platelets & $|96.82 \pm 9| .78$ & $182.33 \pm 85.66$ & $0.73^{\$}$ & 0.47 \\
\hline Uric acid $\mathrm{mg} / \mathrm{dL}$ & $6.96 \pm 2.04$ & $6.65 \pm 1.30$ & $-1.32^{\#}$ & 0.19 \\
\hline Urea (mg/dL) & $42.63 \pm 17.52$ & $38.64 \pm|4.2|$ & $1.10^{\#}$ & 0.39 \\
\hline Creatinine $(\mathrm{mg} / \mathrm{dL})$ & $0.94 \pm 0.18$ & $0.96 \pm 0.16$ & $-0.58^{\#}$ & 0.57 \\
\hline eGFR (mL/min) & $87.36 \pm 15.23$ & $88.51 \pm 14.99$ & $-0.34^{\#}$ & 0.73 \\
\hline
\end{tabular}

Notes: ${ }^{*} \mathrm{Chi}^{2,}{ }^{*}$ t-test, ${ }^{\$}$ Mann-Whitney test.

Abbreviations: ALT, alanine aminotransferase; AST, aspartate aminotransferase; ALP, alkaline phosphatase; INR, International Normalized Ratio; HCC, hepatocellular carcinoma; CRP, C reactive protein; $\mathrm{Hb}$, hemoglobin; WBCs, white blood cells; eGFR, estimated glomerular filtration rate; Tx, transplantation.

end of treatment compared to pretreatment levels. However, within 6 months after completion of treatment, eGFR was recovered to $81.51 \mathrm{~mL} / \mathrm{min}$, which was not significant when compared to baseline eGFR. In patients treated with sofosbuvir plus daclatasvir (group II), only uric acid was significantly increased at the end of treatment compared to pre-treatment level. The difference between the two groups regarding eGFR, creatinine, and urea could be due to the longer treatment duration of the Sofosbuvir/ribavirin regimen compared to the sofosbuvir/ 


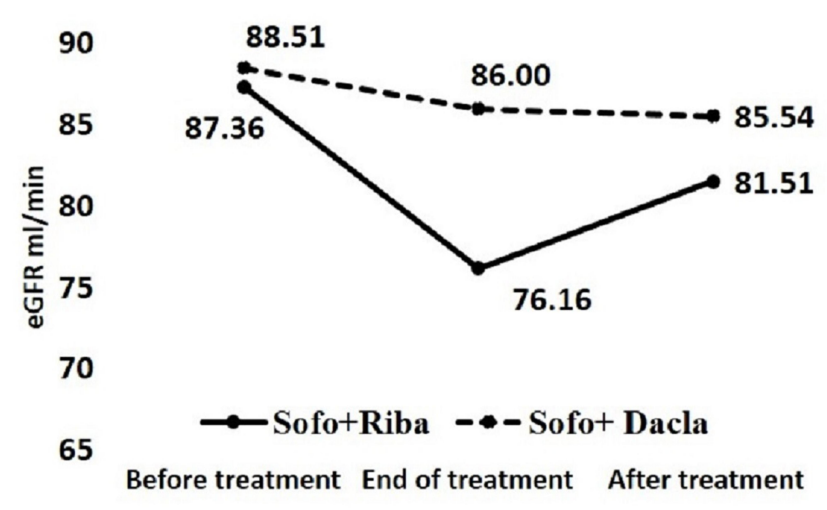

Figure I eGFR before treatment, end of treatment, and 6 months after completing treatment in studied groups.

daclatasvir regimen at 24 and 12 weeks, respectively. Also, the average serum calcineurin inhibitors (CNI) were higher in group I compared to group II, with a higher dose-dependent nephrotoxic potential, although the difference was not statistically significant. ${ }^{33}$ Moreover, potential ribavirin induced tubular toxicity has been hypothesized. Yet, ribavirin renal toxicity has not been documented. ${ }^{34,35}$
In the current study, elevated serum uric acid level was demonstrated at the end of treatment in both groups, which is supported by the outcome of a study conducted by Sato et $\mathrm{al}^{36}$ with elevated uric acid level after sofosbuvir/ribavirin treatment regimen in HCV positive patients without liver transplantation. The exact mechanism is unknown; however, the effect of the metabolite of sofosbuvir has been postulated as a possible mechanism. Also, ribavirin hemolytic effect could explain the same. ${ }^{37}$ Interestingly, there was a close association between elevated uric acid level and elevated creatinine level, which is consistent with the finding in our study regarding the significant elevated creatinine level in group I compared to group II at the end of treatment. ${ }^{36}$ Furthermore, hyperuricemia is a well-known complication after liver transplantation. ${ }^{38}$ Finally, serum uric acid levels improved 6 months after completion of treatment.

Data from different studies on the treatment of HCV postLT using DAAs with and without Ribavirin is restricted in number. Ciesek et $\mathrm{al}^{39}$ found that ribavirin was discontinued in more than half of the patients treated with Ledipasvir/ Sofosbuvir with ribavirin. The most common cause of this

Table 2 Comparison of Laboratory Data Before and After Treatment with DAAs

\begin{tabular}{|c|c|c|c|c|c|c|}
\hline \multirow[t]{2}{*}{ Variables } & \multicolumn{3}{|c|}{$\begin{array}{l}\text { Group I Sofosbuvir + Ribavirin } \\
(n=5 I)\end{array}$} & \multicolumn{3}{|c|}{$\begin{array}{l}\text { Group II Sofosbuvir + Daclatasvir } \\
(n=33)\end{array}$} \\
\hline & Pre-treatment & $\begin{array}{l}\text { Post-treatment } \\
\text { (EOT 24) }\end{array}$ & $P^{*}$ & Pre-treatment & $\begin{array}{l}\text { Post-treatment } \\
\text { (EOT I2) }\end{array}$ & $P^{*}$ \\
\hline Tacrolimus trough level (ng/mL) & $6.67 \pm 3.43$ & $5.99 \pm 3.27$ & 0.10 & $6.00 \pm 2.08$ & $5.83 \pm 1.73$ & 0.65 \\
\hline Ciclosporin C2 level (ng/mL) & $365.92 \pm 132.55$ & $439.42 \pm 163.84$ & 0.28 & $350.14 \pm 84.89$ & $478.57 \pm 152.58$ & 0.052 \\
\hline Bilirubin (mg/dL) & $1.08 \pm 0.47$ & $1.56 \pm 1.79$ & 0.048 & $1.09 \pm 0.55$ & $1.20 \pm 0.75$ & 0.12 \\
\hline Albumin $(g / L)$ & $3.82 \pm 0.75$ & $3.8 I \pm 0.79$ & 0.93 & $3.98 \pm 0.55$ & $4.00 \pm 0.59$ & 0.80 \\
\hline ALT (IU/L) & $45.20 \pm 22.83$ & $52.10 \pm 33.01$ & 0.014 & $49.21 \pm 24.71$ & $50.12 \pm 36.67$ & 0.91 \\
\hline AST (IU/L) & $55.7 I \pm 40.36$ & $62.33 \pm 42.15$ & 0.034 & $43.88 \pm 17.91$ & $48.70 \pm 37.35$ & 0.42 \\
\hline ALP (IU/L) & $234.57 \pm 205.45$ & $247.02 \pm 192.42$ & 0.42 & $202.70 \pm 112.69$ & $|96.55 \pm 98.2|$ & 0.64 \\
\hline INR & $0.99 \pm 0.07$ & $1.04 \pm 0.12$ & 0.014 & $1.02 \pm 0.11$ & $1.04 \pm 0.13$ & 0.63 \\
\hline $\mathrm{Hb} \mathrm{Alc}$ & $5.66 \pm 1.26$ & $5.53 \pm 1.23$ & 0.28 & $5.62 \pm 0.99$ & $5.69 \pm 0.94$ & 0.48 \\
\hline $\mathrm{Na}(\mathrm{mmol} / \mathrm{L})$ & $|35.4| \pm 4.28$ & $|36.5| \pm 3.79$ & 0.07 & $135.76 \pm 3.93$ & $|36.58 \pm 3.6|$ & 0.26 \\
\hline $\mathrm{K}(\mathrm{mmol} / \mathrm{L})$ & $4.44 \pm 0.50$ & $4.48 \pm 0.56$ & 0.59 & $4.60 \pm 0.56$ & $4.33 \pm 0.61$ & 0.11 \\
\hline CRP & $7.35 \pm 5.35$ & $8.99 \pm 7.76$ & 0.07 & $8.29 \pm 6.50$ & $8.07 \pm 7.10$ & 0.87 \\
\hline $\mathrm{Hb}(\mathrm{g} / \mathrm{dL})$ & $|3.2| \pm 2.0 \mid$ & $13.07 \pm 20.00$ & $0.4 I$ & $13.64 \pm 1.63$ & $13.7 \pm 1.8$ & 0.54 \\
\hline WBCs & $6.07 \pm 1.93$ & $6.50 \pm 2.34$ & 0.06 & $5.63 \pm 1.99$ & $6.13 \pm 3.82$ & 0.34 \\
\hline Platelets & $196.82 \pm 9 \mid .78$ & $157.04 \pm 68.36$ & 0.001 & $182.33 \pm 85.66$ & $|47.6| \pm 65.65$ & 0.002 \\
\hline Uric acid (mg/dL) & $6.96 \pm 2.04$ & $8.30 \pm 2.58$ & 0.001 & $6.65 \pm 1.30$ & $7.79 \pm 2.41$ & 0.04 \\
\hline Urea (mg/dL) & $42.63 \pm 17.52$ & $64.49 \pm 46.77$ & 0.001 & $38.64 \pm|4.2|$ & $45.18 \pm 26.77$ & 0.15 \\
\hline Creatinine (mg/dL) & $0.94 \pm 0.18$ & $1.14 \pm 0.47$ & 0.003 & $0.96 \pm 0.16$ & $0.99 \pm 0.19$ & 0.30 \\
\hline eGFR (mL/min) & $87.36 \pm 15.23$ & $76.16 \pm 22.40$ & 0.001 & $88.51 \pm 14.99$ & $86.00 \pm 16.13$ & 0.29 \\
\hline
\end{tabular}

Note: *P-value for $t$-test.

Abbreviations: ALT, alanine aminotransferase; AST, aspartate aminotransferase; INR, International Normalized Ratio; ALP, alkaline phosphatase; CRP, c-reactive protein; $\mathrm{Hb}$, hemoglobin; WBCs, white blood cells; eGFR, estimated glomerular filtration rate. 


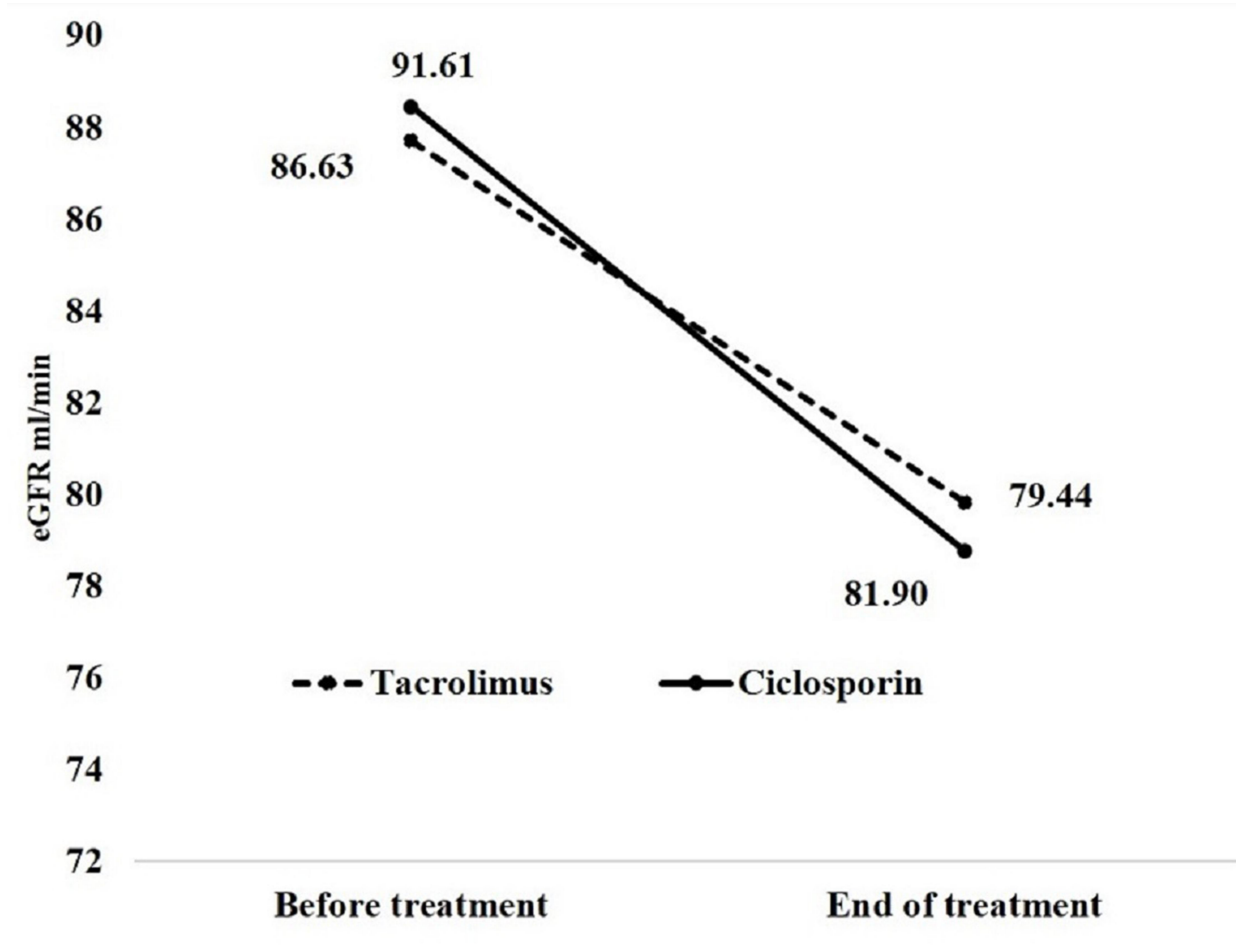

Figure 2 eGFR before and at end of treatment in patients who received Ciclosporin and Tacrolimus.

stoppage of ribavirin is anemia; however, the creatinine level was not significantly changed after the end of therapy compared to pretreatment measurement.

Another study demonstrated a non-significant decline of eGFR from $66.8 \mathrm{~mL} / \mathrm{min}$ to $64 \mathrm{~mL} / \mathrm{min}$ in approximately $82 \%$ of HCV-positive patients with chronic kidney disease stage 2 or 3 after LT during treatment with sofosbuvir plus ledipasvir without ribavirin. ${ }^{40}$ Shoreibah et $\mathrm{al}^{41}$ found that eGFR in $65 \%$ and $35 \%$ of liver transplant recipients was stable or worsened, respectively, in $\mathrm{HCV}-$ positive patients who received sofosbuvir/ledipasvir without ribavirin. Patients with impaired renal function before treatment (eGFR $<60 \mathrm{~mL} / \mathrm{min}$ ) represent the highest proportion (48\%) of those with worsened GFR 3-6 months after treatment. In a study by Peschel et al, ${ }^{10}$ renal function was not affected in immunosuppressed LT recipients during DAAs therapy, even in patients with renal dysfunction at time of therapy with DAAs. Also, in a study by Skoglund et $a l,{ }^{29}$ DAAs were reported to be safe and well tolerated during both pre- and early post-liver transplantation periods. Those previously mentioned studies, together with our results, offer a reassuring data regarding the renal safety of DAAs therapy in post-LT HCV patients with a very promising efficacy profile. Finally, the introduction of DAAs showed a significant improvement in the management of HCV infection after LT.

Based on our results, there is no significant difference regarding eGFR before and at the end of treatment between patients who received either cyclosporine or tacrolimus. Also, there is no significant drug-drug interactions between any of the immunosuppressive drugs or the DAAs used in our study. We did not encounter any significant increase or decrease in serum tacrolimus or cyclosporine trough levels, or any significant changes in the immunosuppression doses required for the patients in the two groups to maintain adequate trough levels. Overall, with close follow-up, immunosuppressive management was relatively successful.

Different studies have reported mixed findings on the drug-drug interactions between immunosuppressants and DAAs. ${ }^{12-16,29,42}$ Similar to our results, Mansour et $\mathrm{al}^{42}$ showed no adjustment to immunosuppression was necessary due to drug-drug interaction from the DAAs included in their study. Charlton et $\mathrm{al}^{13}$ reported that one of the patients experienced an increase in cyclosporine concentrations that the investigator attributed to an interaction with the study treatment regimen. However, this may slightly be caused by more metabolism of the CNI as a 
result of recovery in hepatic function due to viral eradication. Moreover, Pungpapong et $\mathrm{al}^{12}$ showed that doses of cyclosporine or tacrolimus need to be slightly higher to set them at therapeutic range. On the contrary, Peschel et al ${ }^{10}$ reported that cyclosporine dosing required reduction during DAAs treatment in five patients and increased in two patients, While tacrolimus dosing was reduced in one patient and increased in six patients.

Our study showed the advantage of assessing the renal safety of DAAs in post-LT patients with HCV infection. Also, we assessed the immunosuppressive drug levels to evaluate any drug interaction that may require dose adjustment of immunosuppressive drugs. Moreover, patients were followed post-treatment to check if any change of eGFR is permanent.

This study has the following limitations. Patients with moderate or severe renal impairment were not included. The retrospective study design may lead to under-reporting of side-effects, and there was a relatively small number of patients in each treatment arm. A large cohort study including patients with all CKD stages is highly warranted.

\section{Conclusions}

Treatment of HCV positive patients with DAAs after liver transplantation is effective and well tolerated. eGFR has been declined in association with elevated creatinine and uric acid levels at the end of treatment. However, all values approximately regain the pretreatment levels within 6 months after completion of therapy. Overall renal function remained stable, albeit sofosbuvir plus daclatasvir regimen is relatively safer as compared to sofosbuvir plus ribavirin.

\section{Disclosure}

The authors report no conflicts of interest in this work.

\section{References}

1. Organization, W.H.. Guidelines for the care and treatment of persons diagnosed with chronic hepatitis C virus infection. 2018.

2. Modin L, Arshad A, Wilkes B, et al. Epidemiology and natural history of hepatitis $\mathrm{C}$ virus infection among children and young people. $J$ Hepatol. 2019;70(3):371-378. doi:10.1016/j.jhep.2018.11.013

3. Germani G, Tsochatzis E, Papastergiou V, Burroughs A. HCV in liver transplantation. Semin Immunopathol. 2013;35:101-110. doi:10.1007/ s00281-012-0329-5

4. Narang TK, Ahrens W, Russo MW. Post-liver transplant cholestatic hepatitis $\mathrm{C}$ : a systematic review of clinical and pathological findings and application of consensus criteria. Liver Transpl. 2010;16 (11):1228-1235. doi:10.1002/1t.22175

5. Daniel KE, Said A. Considerations when treating hepatitis $\mathrm{C}$ in a cirrhotic transplant candidate. Curr Gastroenterol Rep. 2018;20 (5):20. doi:10.1007/s11894-018-0626-9
6. Gurusamy KS, Tsochatzis E, Xirouchakis E, Burroughs AK, Davidson BR. Antiviral therapy for recurrent liver graft infection with hepatitis C virus. Cochrane Library. 2010.

7. Liver EAFTSOT. EASL recommendations on treatment of hepatitis C 2016. J Hepatol. 2017;66(1):153.

8. Chung R, Davis G, Jensen D. AASLD/IDSA HCV Guidance Panel. Hepatitis C guidance: AASLD-IDSA recommendations for testing, managing, and treating adults infected with hepatitis $\mathrm{C}$ virus. Hepatology. 2015;62(3):932-954.

9. Majumdar A, Kitson M, Roberts S. Systematic review: current concepts and challenges for the direct-acting antiviral era in hepatitis $\mathrm{C}$ cirrhosis. Aliment Pharmacol Ther. 2016;43(12):1276-1292.

10. Peschel G, Moleda L, Baier L, et al. Safety of direct-acting antiviral therapy regarding renal function in post-liver transplant patients infected with Hepatitis C virus and a 100\% 12-week sustained virologic response - a single-center study. In: Transplantation Proceedings. 2018;50(5):1444-1450.

11. Charlton M, Gane E, Manns P, et al. Sofosbuvir and ribavirin for treatment of compensated recurrent hepatitis $\mathrm{C}$ virus infection after liver transplantation. Gastroenterology. 2015;148(1):108-117. doi:10.1053/j.gastro.2014.10.001

12. Pungpapong S, Aqel B, Leise M. Multicenter experience using simeprevir and sofosbuvir with or without ribavirin to treat hepatitis $\mathrm{C}$ genotype 1 after liver transplant. Hepatology. 2015;61(6):1880-1886. doi: $10.1002 /$ hep. 27770

13. Charlton M, Everson G, Steven L, et al. Ledipasvir and sofosbuvir plus ribavirin for treatment of $\mathrm{HCV}$ infection in patients with advanced liver disease. Gastroenterology. 2015;149(3):649-659. doi:10.1053/j.gastro.2015.05.010

14. Leroy V, Dumortier J, Coilly A, et al. Efficacy of sofosbuvir and daclatasvir in patients with fibrosing cholestatic hepatitis $\mathrm{C}$ after liver transplantation. Clin Gastroenterol Hepatol. 2015;13(11):1993-2001. e2. doi:10.1016/j.cgh.2015.05.030

15. Fontana RJ, Brown RS, Moreno-Zamora A, et al. Daclatasvir combined with sofosbuvir or simeprevir in liver transplant recipients with severe recurrent hepatitis C infection. Liver Transpl. 2016;22(4):446458. doi:10.1002/lt.24416

16. Poordad F, Schiff ER, Vierling JM, et al. Daclatasvir with sofosbuvir and ribavirin for hepatitis $\mathrm{C}$ virus infection with advanced cirrhosis or post-liver transplantation recurrence. Hepatology. 2016;63(5):14931505. doi:10.1002/hep.28446

17. Reau N, Kwo PY, Rhee S. MAGELLAN-2: safety and efficacy of glecaprevir/pibrentasvir in liver or renal transplant adults with chronic hepatitis C genotype 1-6 infection. J Hepatol. 2017;66(1): S90-S91. doi:10.1016/S0168-8278(17)30444-0

18. Nada A, Abbasy M, Sabry A, et al. Serum Neutrophil GelatinaseAssociated Lipocalin (NGAL) in HCV-positive Egyptian patients treated with sofosbuvir. Can J Gastroenterol Hepatol. 2020;2020:17. doi:10.1155/2020/1632959

19. Levey AS, Stevens LA, Schmid CH, et al. A new equation to estimate glomerular filtration rate. Ann Intern Med. 2009;150 (9):604-612. doi:10.7326/0003-4819-150-9-200905050-00006

20. Andrews LM, Riva N, de Winter BC, et al. Dosing algorithms for initiation of immunosuppressive drugs in solid organ transplant recipients. Expert Opin Drug Metab Toxicol. 2015;11(6):921-936. doi:10.1517/17425255.2015.1033397

21. Gadiparthi C, Cholankeril G, Perumpail BJ, et al. Use of direct-acting antiviral agents in hepatitis $\mathrm{C}$ virus-infected liver transplant candidates. World J Gastroenterol. 2018;24(3):315. doi:10.3748/wjg.v24.i3.315

22. Picciotto FP, Tritto G, Lanza AG, et al. Sustained virological response to antiviral therapy reduces mortality in $\mathrm{HCV}$ reinfection after liver transplantation. $J$ Hepatol. 2007;46(3):459-465. doi:10.1016/j.jhep.2006.10.017

23. Ferrarese A, Zanetto A, Gambato M, et al. Liver transplantation for viral hepatitis in 2015. World J Gastroenterol. 2016;22(4):1570. doi:10.3748/wjg.v22.i4.1570 
24. Coilly A, Roche B, Duclos-Vallée JC, Samuel D. Optimum timing of treatment for hepatitis $\mathrm{C}$ infection relative to liver transplantation. Lancet Gastroenterol Hepatol. 2016;1(2):165-172. doi:10.1016/ S2468-1253(16)30008-5

25. Samur S, Kues B, Ayer T, et al. Cost effectiveness of pre-vs postliver transplant hepatitis $\mathrm{C}$ treatment with direct-acting antivirals. Clin Gastroenterol Hepatol. 2018;16(1):115-122. e10. doi:10.1016/ j.cgh.2017.06.024

26. Levitsky J, Verna EC, O’Leary JG, et al. Perioperative ledipasvirsofosbuvir for $\mathrm{HCV}$ in liver-transplant recipients. $N \mathrm{Engl} \mathrm{J} \mathrm{Med.}$ 2016;375(21):2106. doi:10.1056/NEJMc1611829

27. Younossi ZM, Stepanova M, Charlton M, et al. Patient-reported outcomes with sofosbuvir and velpatasvir with or without ribavirin for hepatitis $\mathrm{C}$ virus-related decompensated cirrhosis: an exploratory analysis from the randomised, open-label ASTRAL-4 phase 3 trial. Lancet Gastroenterol Hepatol. 2016;1(2):122-132. doi:10.1016/ S2468-1253(16)30009-7

28. Ferenci P. Treatment of hepatitis $\mathrm{C}$ in difficult-to-treat patients. Nat Rev Gastroenterol Hepatol. 2015;12(5):284. doi:10.1038/ nrgastro.2015.53

29. Skoglund C, Lagging M, Castedal M, Kanda T. No need to discontinue hepatitis $\mathrm{C}$ virus therapy at the time of liver transplantation. PLoS One. 2019;14(2):e0211437. doi:10.1371/journal.pone.0211437

30. Rupp C, Hippchen T, Neuberger M, et al. Successful combination of direct antiviral agents in liver-transplanted patients with recurrent hepatitis C virus. World J Gastroenterol. 2018;24(12):1353. doi:10.3748/wjg.v24.i12.1353

31. D’Ambrosio R, Aghemo A, Rumi MG, et al. A morphometric and immunohistochemical study to assess the benefit of a sustained virological response in hepatitis $\mathrm{C}$ virus patients with cirrhosis. Hepatology. 2012;56(2):532-543. doi:10.1002/hep.25606

32. Welsch C, Efinger M, von Wagner M, et al. Ongoing liver inflammation in patients with chronic hepatitis $\mathrm{C}$ and sustained virological response. PLoS One. 2017;12(2):e0171755. doi:10.1371/journal. pone. 0171755

33. Naesens M, Kuypers DR, Sarwal M. Calcineurin inhibitor nephrotoxicity. Clin J Am Soc Nephrol. 2009;4(2):481-508. doi:10.2215/ CJN.04800908
34. Fabrizi F, Aghemo A, Fogazzi GB, et al. Acute tubular necrosis following interferon-based therapy for hepatitis $\mathrm{C}$ : case study with literature review. Kidney Blood Press Res. 2013;38(1):52-60. doi:10.1159/000355753

35. Kökény S, Papp J, Weber G, Vaszkó T, Carmona-Saez P, Oláh E. Ribavirin acts via multiple pathways in inhibition of leukemic cell proliferation. Anticancer Res. 2009;29(6):1971-1980.

36. Sato K, Naganuma A, Nagashima T, et al. Elevated serum uric acid level was a notable adverse event during combination therapy with sofosbuvir and ribavirin. Hepatol Res. 2018;48(3):E347-e353. doi:10.1111/hepr.12971

37. Knorr JP, Chewaproug D, Neeli S, Torres E, Zaki R. Severe interferon/ribavirin-induced hyperuricemia and urate nephropathy requiring rasburicase and hemodialysis in a liver transplant recipient. Exp Clin Transplant. 2015;13(6):596-599.

38. Harambat J, Dubourg L, Ranchin B, et al. Hyperuricemia after liver transplantation in children. Pediatr Transplant. 2008;12(8):847-853. doi:10.1111/j.1399-3046.2008.00950.x

39. Ciesek S, Proske V, Otto B, et al. Efficacy and safety of sofosbuvir/ ledipasvir for the treatment of patients with hepatitis $\mathrm{C}$ virus reinfection after liver transplantation. Transpl Infect Dis. 2016;18 (3):326-332. doi:10.1111/tid.12524

40. Pillai AA, Maheshwari R, Vora R, et al. Treatment of HCV infection in liver transplant recipients with ledipasvir and sofosbuvir without ribavirin. Aliment Pharmacol Ther. 2017;45(11):1427-1432. doi:10.1111/apt.14059

41. Shoreibah O, John Romano J, Sims TM, et al. Effect of Hepatitis C treatment on renal function in liver transplant patients. J Clin Transl Hepatol. 2018;6(4):391-395.

42. Mansour M, Hill L, Kerr J. Safety and effectiveness of direct acting antivirals for treatment of hepatitis $\mathrm{C}$ virus in patients with solid organ transplantation. Transpl Infect Dis. 2018;20(6):e12972. doi:10.1111/tid.12972
The International Journal of Nephrology and Renovascular Disease is an international, peer-reviewed open-access journal focusing on the pathophysiology of the kidney and vascular supply. Epidemiology, screening, diagnosis, and treatment interventions are covered as well as basic science, biochemical and immunological studies. The manuscript management system is completely online and includes a very quick and fair peer-review system, which is all easy to use. Visit http://www.dovepress.com/testimonials.php to read real quotes from published authors. 